\title{
Centralised horizontal cooperation and profit sharing in a shipping pool
}

\author{
Wen, Min; Larsen, Rune; Røpke, Stefan; Petersen, Hanne Løhmann; Madsen, Oli B.G.
}

Published in:

Journal of the Operational Research Society

Link to article, DOI:

$10.1080 / 01605682.2018 .1457481$

Publication date:

2019

Document Version

Peer reviewed version

Link back to DTU Orbit

Citation (APA):

Wen, M., Larsen, R., Røpke, S., Petersen, H. L., \& Madsen, O. B. G. (2019). Centralised horizontal cooperation and profit sharing in a shipping pool. Journal of the Operational Research Society, 70(5), 737-750. https://doi.org/10.1080/01605682.2018.1457481

\section{General rights}

Copyright and moral rights for the publications made accessible in the public portal are retained by the authors and/or other copyright owners and it is a condition of accessing publications that users recognise and abide by the legal requirements associated with these rights.

- Users may download and print one copy of any publication from the public portal for the purpose of private study or research.

- You may not further distribute the material or use it for any profit-making activity or commercial gain

- You may freely distribute the URL identifying the publication in the public portal 


\title{
Centralized horizontal cooperation and profit sharing in a shipping Pool
}

\author{
Min Wen ${ }^{1}$, Rune Larsen ${ }^{2}$, Stefan Ropke ${ }^{2}$, Hanne L. Petersen ${ }^{2}$ and Oli B.G. Madsen ${ }^{2}$ \\ ${ }^{1}$ Department of Mathematical Science, Xi'an Jiaotong-Liverpool University, 111 Ren Ai \\ Road, Suzhou, Jiangsu, 215123, China, min.wen@xjtlu.edu.cn \\ ${ }^{2}$ Department of Management Engineering, Technical University of Denmark, \\ Produktionstorvet 424, DK-2800 Kongens Lyngby, Denmark, rular@dtu.dk, \\ ropke@dtu.dk, halpe@sdfe.dk, omg@dtu.dk
}

\begin{abstract}
Horizontal cooperation in logistics has attracted an increasing amount of attention in both industry and the research community. The most common form of cooperation in the tramp shipping market is the shipping pool, formed by a fleet of ships from different ownerships operated by a centralized administration. This paper studies such a centralized horizontal cooperation, a product tanker pool in Denmark, and addresses the operational challenges, including how to maximize the pool profit and how to allocate it fairly.

We apply discrete event simulation and dynamic ship routing and speed optimization in order to maximize the pool profit in a highly dynamic environment and apply methods derived from cooperative game theory when allocating the total profit. Through a large number of experiments on realistic data, we evaluate the benefit of cooperation under different scenarios, present the results from the profit allocation and analyse the effect of pool size on the total profit and ship utilization rate.
\end{abstract}

Keywords: Centralized horizontal cooperation; shipping pools; fullshipload routing problem; profit sharing

\section{Introduction}

Horizontal cooperation is the practice of cooperation between companies operating at the same level(s) of a supply chain. By teaming up with other operators in the market, each company can pool resources and obtain benefits due to economies of scale. Each participant in the cooperation may gain access to new customers and may reduce income fluctuations. By being part of a larger group, losses in some areas, that could be disastrous for a small participant, can be offset by income made by other participants of the 
coalition (Cruijssen et al. (2007), Willems et al. (2010) and Schmoltzi and Wallenburg (2011)). Depending on whether individual participants have control over system operations, cooperations can be classified as either centralized or decentralized. In a centralized cooperation, a central manager with complete information about all participants makes the optimal decisions to achieve the common objectives and then divides the resulting benefits between the participant (Krajewska et al. (2008); Audy et al. (2011)). In the decentralized system, the participants only share partial information, and individual participants have control over their own resources and selfishly make their own decisions to maximize their own benefits (Özener et al. (2011); Agarwal and Ergun (2010a)).

This work focuses on a centralized horizontal cooperation in the tramp shipping market in the form of shipping pool. The collaboration treated in this paper has several characteristics that differentiate it from other centralized horizontal collaborations treated in the literature: 1) The ships are operated as long haul vehicles with limited knowledge of future orders, leading to a high degree of dynamism. 2) The ships are expensive to operate and profit margins are tight, meaning that the variance in the obtained profits is important and missed orders are more likely to have a significant negative impact on the economy of the shipowner. 3) Compared to truck based transport each owner operates a smaller number of vessels and geographically the orders are sparse and the trade pattern can be asymmetric. Ships will be more likely to struggle to chain together profitable orders and might risk sailing empty rather than having less profitable orders to fall back on. 4) Maintaining reputation among regular customers makes servicing a subset of geographically homogenous orders a priority. This places an emphasis on maintaining the availability of ships in a given area. An overview of cooperation in tramp shipping in different sectors is provided in Clarkson Research Studies (2004) and Rodrigo (2007). An overview of shipping pool establishment, administration, operations, etc. can be found in Packard (1995).

The main contribution of this paper is an analysis of the benefits involved in horizontal collaboration in tramp shipping, exemplified on a shipping pool of product tankers. We believe our work is a first effort to capture the differences outlined above. We propose a simulation based on dynamic reoptimization since an important advantage of pooling ships is the higher chance of being near profitable orders as they appear. We also generate a set of orders reflecting the prevalence of regular customers. We evaluate the results with an emphasis on the variance in profitability as participants cannot run at a deficit for an extended period of time. We compare the benefits of cooperation under different scenarios, present profit allocation results and analyse the impact of pool size on the total profit and ship utilization.

The remainder of the paper is organized as follows. Section 2 introduces the concept of shipping pools. Section 3 reviews relevant literature with the aim of describing how the paper at hand is positioned compared to existing literature. Section 4 describes the proposed decision support framework for simulating the operations and profit sharing in the shipping pool. Section 5 presents the case study while the computational results are given in Section 6. Conclusions can be found in Section 7. 


\section{Shipping pools}

A shipping pool generally brings together a number of vessels that are under different ownership but of a similar type and usually operated under a single administration (e.g. a pool manager), which is responsible for the commercial management. Shipping pools is a common form of centralized horizontal collaboration in the shipping industry. They provide several benefits to participants: ability to undertake contracts of affreightment, better fleet utilization, a stronger marketing position, flexibility, risk sharing, income stabilization, and economies of scale (Haralambides, 1996). In shipping pools, the pool administration will market the vessels as a single fleet, collect the earnings, and distribute them using some pre-arranged system, in which each entered vessel should receive a fair share of the total profits (Packard, 1995). The pool administrator may also handle fuelling, port costs, insurance, and similar areas, and be able to exploit economies of scale when doing so.

In this work, we study a Danish product tanker pool. The pool consists of 32 product tankers from different shipping companies. We focus primarily on the operational challenges, including 1) how to maximize the overall profit and 2) how to fairly allocate the profit to the participants.

The first question can be answered by optimizing the ship routing and scheduling. Given a set of received orders, the purpose is to select the orders to serve and to decide the optimal routes for the ships to maximize the overall profit. In our case, the cargoes should be transported directly from their load ports to their discharge ports, the ship can carry at most one cargo at a time and the ship speed on each leg should be determined. Hence, the problem is essentially a full-shipload combined ship routing and speed optimization problem. A mixed integer programming formulation for this problem as well as a heuristic solution method will be presented in Section 4.3.

The second question is related to the profit sharing problem. The pool manager must ensure that there is enough incentive for the participants to stay in the pool and support the decisions made by the manager, and all participants must perceive the profit distribution as fair. In most shipping pools, a weighing and distribution system is defined based on the pool's 'reference vessel'. The reference vessel has ideal characteristics in vessel size, weight, capacity, age, flag, trading limitation, speed, fuel consumption, etc. Each pooled ship is compared to the reference vessel and assigned a resulting score describing the ships perceived value to the pool. This score decides the ship's share of the total pool net revenue. In the shipping pool studied in this work, points are also assigned according to whether the vessel follows the given speed orders and whether the actual fuel consumption is in line with the expected fuel consumption (according to the given speed orders). However, as Haralambides (1996) points out, a formula-based distribution system may be unfair in terms of profit sharing. In this work, we apply other profit allocation methods and test their fairness from a game theoretic point of view (see Section 4.4). 


\section{Literature review}

An important component of the simulations performed in this paper is the ability to solve the routing and order selection problem that a tanker or pool operator faces. This problem can be seen as a variant of the vehicle routing problem (VRP). VRPs have been extensively studied in the literature, and the book by Toth and Vigo (2014) is an excellent starting point. A substantial part of the VRP literature is devoted to ship routing and scheduling, and a recent review of this area is given by Christiansen et al. (2013).

The routing problem that must be solved during the simulation in the paper at hand is a full-shipload routing problem, where each order completely occupies the entire vessel. Such problems have been studied by, for example, Gatica and Miranda (2011), Hwang et al. (2008) and Wen et al. (2016). The latter reference describes the method employed in the computational study of the present paper. In case multiple orders can fit on the ship, a multi-cargo ship routing problem must be solved; such approaches are addressed by, for example, Korsvik et al. (2010), Lin and Liu (2011) and Norstad et al. (2011).

As mentioned in the introduction, it is necessary to solve the tramp shipping problem in a dynamic fashion since we want to simulate the performance of various coalitions over a longer time period and not all the cargoes are known from the beginning of the planning period. The dynamic version of the problem has been less studied in the literature. The only papers that we are aware of that deal with dynamic routing problems in maritime transportation are Tirado et al. (2013), Tirado and Hvattum (2016a) and Tirado and Hvattum (2016b). In their problems, stochastic information on the new cargoes are assumed to be known and are utilized in scenario-based heuristics to produce the solution, whereas no stochastic information is assumed in our case. It is worth mentioning that the literature on dynamic VRP in general is very rich. Some recent surveys of dynamic VRP literature are Pillac et al. (2013), Bektas et al. (2014) and Psaraftis et al. (2016).

The effects of horizontal collaboration in logistics and the following sharing of profits is in general widely studied (Cruijssen et al. (2010), Ergun et al. (2007b), Ergun et al. (2007a) and Schmoltzi and Wallenburg (2011)). Most applications are found within roadbased transportation, including transportation in the forestry industry (Frisk et al., 2010), furniture transportation (Audy et al., 2011), freight carriers (Krajewska et al., 2008), and railway transportation (Sherali and Lunday, 2011). The operations research literature on horizontal collaboration within maritime logistics is sparse, but studies on collaborations within liner shipping alliances and on collaborations between ports exists (liner shipping alliances: Song and Panayides (2002), Agarwal and Ergun (2010b), Yang et al. (2011); port collaboration: Saeed and Larsen (2010), Xu et al. (2015)). While these papers share the maritime application area with the present paper the problems studied and solution methods employed are different from ours.

We are not aware of any operations research papers that study collaboration in shipping pools for the tramp shipping market and we are not aware of any papers that study horizontal collaboration where profit estimations are based on solving dynamic vehicle routing problems, which are two central themes in this paper. 


\section{Simulating horizontal cooperation in a shipping pool}

The Danish product tanker pool studied in this work is formed by a fleet of product tankers that are of different ownership but operated by one pool manager. The pool manager controls the entire fleet of vessels, assigns orders, determines the movement of each vessel during operation, and decides the allocation of profits among the participants.

We simulate the operations in the shipping pool by dynamic rescheduling. The simulation is updated as orders are revealed over time, and the schedules for the ships are replanned dynamically by solving a routing problem. After a certain amount of simulated time has passed, i.e., every 6 months, the gained profit is shared among the pool participants.

\subsection{Distance calculations}

The simulation is performed on a network of via points overlaid onto the oceans, which allows us to create a matrix of sea distances between all harbours in the model (for an alternative method for computing sea distances, see Fagerholt et al. (2000)). Special orders, such as those passing the Panama Canal or The North East Passage, are also taken into account. Some regions are classified as requiring ice class certification. These regions can only be traversed by a subset of the available ships.

\subsection{Simulator}

The simulator has full information about the current location and the currently assigned schedule of each ship at any time during the operation. The simulator reveals new orders generated by the order generator and sends these, as well as the ships' information, to the routing solver when updating the schedules of the ships. A branch \& price heuristic for the routing problem determines the most profitable schedules for the ships, i.e., whether the new orders should be accepted, which ship should pick up which cargo at what time, and the speed of each ship on each leg. This corresponds to solving a dynamic ship planning problem with the objective of maximizing the total profit of the shipping pool.

After a certain pre-determined amount of time, the simulator collects performance information from the different vessels and sends it to the profit sharing module, which determines how the profit should be allocated among the participants. A flow diagram depicting the simulation is shown in Figure 1. 


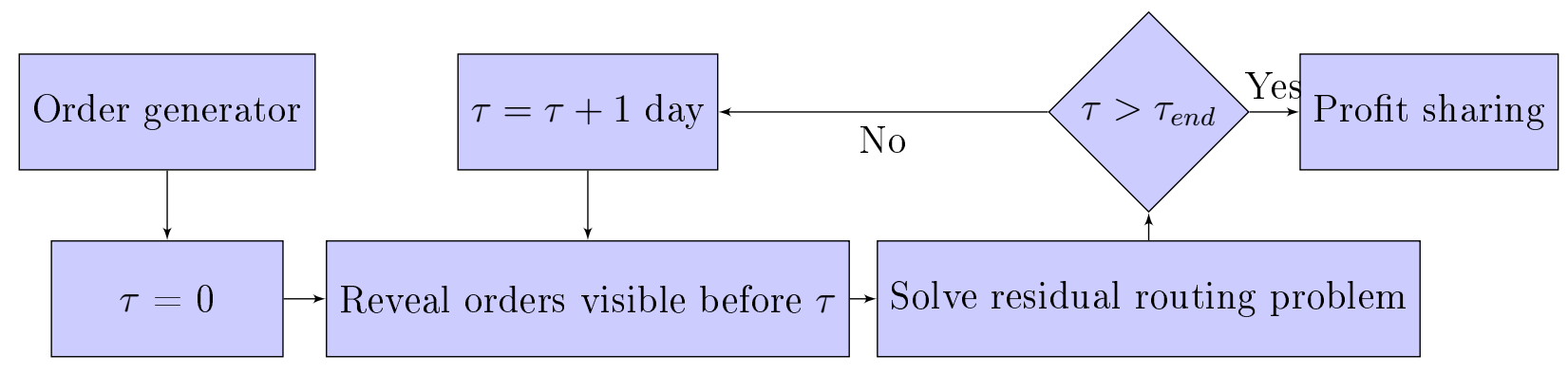

Figure 1: The flow of the simulation

In order to compare coalitions of varying sizes, the subset of orders available to each coalition needs to be determined. This is done by assigning to each ship $s \in S$ a starting port $p(s)$ sampled from the same distributions used to determine the orders' discharge ports. The list of ships is scrambled, and each ship gets to select an order in turn.

Let $R$ be the set of all unassigned orders, and $R_{s}$ be the set of orders assigned to ship $s$. Let $P_{s}$ be the set of ports associated with ship $s$, i.e., $P_{s}$ contains $p(s)$ and the first and last port of each of the orders $j \in R_{s}$. The next order $r$ to assign to ship $s$ is then found using the following formula:

$$
r=\arg \min _{r \in R}\left(\sum_{p \in P_{s}}\left(d_{r_{o} p}+d_{r_{d} p}\right)\right)
$$

The set of orders available to a coalition is the union of the sets available to the ships in the coalition. This allocation method tends to assign orders which are geographically clustered to a single ship, increasing the likelihood that even small coalitions can find routes that involve little empty sailing.

\subsection{Solving the routing problem}

The routing problem is essentially a full-shipload routing and speed optimization problem. A number of cargoes with specified pick-up time windows can be transported from load to discharge ports using a fleet of heterogeneous ships of different speed ranges and fuel consumptions. The ships can sail at certain discretised speeds. For each ship, the fuel consumption depends on the shipload (ballast or laden) and sailing speed, and is obtained from real-life data. The objective of the problem is to determine the cargoes to be served, the optimal route for each ship and the optimal sailing speed for each leg on the route such that the total profit of the shipping pool is maximized.

This problem can be defined on the graph $G=(N, A)$, where $N$ is the set of all the nodes and $A$ is the set of feasible arcs in the graph. Let $S$ denote the set of ships. Each ship $s \in S$ starts from node $o(s)$ and ends at dummy node $d(s)$. Let $O$ and $D$ denote the set of all origins and destinations of the ships. Let $N_{0}$ denote the set of cargoes. As this is a full-shipload problem, each node $i \in N_{0}$ corresponds to a cargo transported directly from its load port to its discharge port, and is associated with a sailing distance $g_{i}$ from the load port to the discharge port, a port service time $t_{i}$ for loading and unloading the cargo and a time window $\left[a_{i}, b_{i}\right]$, within which the cargo should start being loaded. For 
$i \in O \cup D$, we set $g_{i}=0, t_{i}=0, a_{i}=0$ and $b_{i}=\max _{j \in N_{0}}\left\{b_{j}\right\}$. The set of all the nodes is $N=N_{0} \cup O \cup D$. Let $N_{i}^{+}=\{j:(i, j) \in A\}$ and $N_{i}^{-}=\{j:(j, i) \in A\}$ be the set of nodes that can be reached from node $i$ and can reach node $i$, respectively. The distance between two nodes $i$ and $j$ is denoted as $d_{i j}$, which is the distance from the discharge port of cargo $i$, or the location of $i$ if $i \in O$, to the load port of cargo $j$. For the dummy nodes $j \in D$, we set $d_{i j}=0$, since we do not decide in advance where the ship should end its journey. The ships can sail at different speeds. Let $V$ denote the set of speeds and $l^{v}$ the time of sailing one distance unit at speed $v \in V$. The fuel consumption depends on the ship and its sailing speed load. Let $e_{s}^{v}$ denote the fuel cost of ship $s$ sailing empty one distance unit at speed $v$. Let $c_{i s}^{v}$ be the cost of ship $s$ sailing one distance unit at speed $v$ with cargo $i$. It should be noted that $c_{i s}^{v}$ is determined by the light weight of the ship $s$, the weight of cargo $i$ and the speed. Examples of approximation functions of $c_{i s}^{v}$ can be found in Psaraftis and Kontovas (2013). Due to the fact that the ships are different, not all the ships can serve all the cargoes. For example, a small ship cannot carry a large cargo, and a large ship with deep draft cannot serve a cargo with a shallow load or discharge port. Let the binary parameter $p_{i s}$ be 1 if it is feasible for ship $s$ to serve cargo $i$ and 0 otherwise. Let $r_{i}^{v}$ be the reward of cargo $i$ when served at speed $v$.

Let binary variable $x_{i j s}^{v}$ be 1 iff ship s sails from cargo node $i$ to cargo node $j$ at speed $v$, and let binary variable $y_{i s}^{v}$ be 1 iff ship $s$ serves cargo $i$ at speed $v$. Let variable $z_{i s}$ denote the time when ship $s$ starts loading cargo $i$, and auxiliary variable $w_{i j s}$ denote the time span of ship $s$ from arrival at the loading port of cargo $i$ to arrival at the loading port of cargo $j$. The mathematical model can be presented as follows: 


$$
\min \sum_{i \in N_{0}} \sum_{s \in S} \sum_{v \in V} c_{i s}^{v} g_{i} y_{i s}^{v}+\sum_{(i, j) \in A} \sum_{s \in S} \sum_{v \in V} e_{s}^{v} d_{i j} x_{i j s}^{v}-\sum_{i \in N_{0}} \sum_{s \in S} \sum_{v \in V} r_{i}^{v} y_{i s}^{v}
$$

subject to:

$$
\begin{aligned}
& \sum_{j \in N_{i}^{+}} \sum_{s \in S} \sum_{v \in V} x_{i j s}^{v} \leq 1 \quad \forall i \in N_{0} \\
& \sum_{j \in N_{o(s)}^{+}} \sum_{v \in V} x_{o(s) j s}^{v}=1 \quad \forall s \in S \\
& \sum_{j \in N_{i}^{+}} \sum_{v \in V} x_{i j s}^{v}-\sum_{j \in N_{i}^{-}} \sum_{v \in V} x_{j i s}^{v}=0 \quad \forall i \in N_{0}, s \in S \\
& \sum_{j \in N_{d(s)}^{-}} \sum_{v \in V} x_{j d(s) s}^{v}=1 \quad \forall s \in S \\
& t_{i}+\sum_{v \in V} g_{i} l^{v} y_{i s}^{v}+\sum_{v \in V} d_{i j} l^{v} x_{i j s}^{v}=w_{i j s} \quad \forall(i, j) \in A, s \in S \\
& z_{i s}+w_{i j s}-M\left(1-\sum_{v \in V} x_{i j s}^{v}\right) \leq z_{j s} \quad \forall(i, j) \in A, s \in S \\
& a_{i} \leq z_{i s} \leq b_{i} \quad \forall i \in N, s \in S \\
& \sum_{v \in V} y_{i s}^{v} \leq p_{i s} \quad \forall i \in N_{0}, s \in S \\
& \sum_{j \in N_{i}^{+}} \sum_{v \in V} x_{i j s}^{v}=\sum_{v \in V} y_{i s}^{v} \quad \forall i \in N_{0}, s \in S \\
& x_{i j s}^{v}, y_{i s}^{v} \in\{0,1\} \quad \forall i, j \in N, v \in V, s \in S \\
& z_{i s} \geq 0 \quad \forall i \in N, s \in S \\
& w_{i j s} \geq 0 \quad \forall i, j \in N, s \in S
\end{aligned}
$$

The objective function (1) minimizes the sum of the transportation cost minus the total reward of the served cargoes. The problem can also be reformulated as a maximization of the total profit. It should be noted that other ship costs, such as maintenance costs and crew salaries, are not considered in this work. Constraints (2) ensure that each cargo is served by at most one ship at one speed. Constraints (3) to (5) are flow conservation constraints. Constraints (6) calculate the time span $w_{i j s}$ of ship $s \in S$ from the arrival at the loading port of cargo $i$ to the arrival at the loading port of cargo $j$, which is the sum of the loading and unloading time of cargo $i$, the sailing time between the load and discharge ports of cargo $i$ and the sailing time from cargo $i$ to cargo $j$. Constraints (7) impose that if ship $s$ sails from $i$ to $j$, then $z_{j s} \geq z_{i s}+w_{i j s}$. The $M$ used in (7) is a sufficiently big number (see Wen et al. (2016)). Constraints (8) are the time window constraints. Constraints (9) ensure that each cargo is served by a compatible ship. Constraints (10) enforce the relationship between $x$ and $y$ variables. Constraints (11), (12) and (13) define the variables. 
This combined ship routing and speed optimization problem is solved by a Heuristic Branch\&Price (H-B\&P) method as described in Wen et al. (2016). It is a hybrid approach of Branch \& Bound and heuristic Column Generation. The performance of the H-B\&P for the static ship planning problem was tested thoroughly using generated test instances in Wen et al. (2016). It has been found that, even though the H-B\&P does not guarantee optimality because the pricing problem is solved heuristically, it is able to find optimal solutions for small test instances with up to 70 cargoes over a 45-day planning horizon and near-optimal solutions for large instance with up to 190 cargoes over a 105-day planning horizon. For further details on the algorithm and results, we refer to Wen et al. (2016).

\subsection{Profit sharing}

The goal of profit sharing is to distribute the total profit of the shipping pool to each participant according to a certain profit allocation method, which is usually derived from cooperative game theory. In the following, we will introduce some basic notation: Let $C=\{1,2, \ldots, n\}$ be the finite set of different participants in the cooperation, also referred to as the grand coalition. Let the characteristic function $v(S)$ represent the profit that the participants in subset $S \subseteq C$ can achieve by cooperating, also called the stand-alone profit of coalition $S$. Let vector $x=\left\{x^{1}, x^{2}, \ldots, x^{n}\right\}$ denote the profit allocation, where $x^{k}$ represents the profit allocated to participant $k$. An allocation $x$ is said to be 1) efficient, if the total profit of the grand coalition $v(C)$ is divided among the participants, i.e., $\sum_{k \in N} x^{k}=v(C)$; 2) individually rational, if the profit allocated to each participant is greater than or equal to the participant's stand-alone profit, i.e., $x^{k} \geq v(\{k\})$ for each participant $k \in C$; and 3) stable, if, for each coalition $S \subseteq C$, the profit allocated to the participants in the coalition is greater than or equal to the coalition's stand-alone profit, i.e., $\sum_{k \in S} x^{k} \geq v(S)$. The core of a cooperative game is the set of allocations that satisfy the efficiency and stability properties and is widely considered a fair allocation. The core of a game may be empty. When the core is non-empty, there might be multiple core allocations. Then some other desirable properties can be imposed to select a particular solution in the core.

In this work, we have applied six different allocation methods, which will be described below.

\section{Equal profit method (EPM)}

The Equal Profit Method, proposed by Frisk et al. (2010), aims at finding a solution in the core such that the maximal difference in relative savings between all pairs of participants is minimized. In our profit allocation, we adopt the EPM by defining the relative earning of participant $i$ as $\frac{x^{i}-v(\{i\})}{v(\{i\})}$. The difference in relative earning between participant $i$ and

$j$ is calculated as $\frac{x^{i}}{v(\{i\})}-\frac{x^{j}}{v(\{j\})}$. To find this allocation, the following linear programming (LP) model is solved. 


$$
\begin{array}{rlrl}
\min & z & \\
z & \geq \frac{x^{i}}{v(\{i\})}-\frac{x^{j}}{v(\{j\})} \forall i, j \in C \\
\sum_{k \in N} x^{k} & =v(C) & & \\
\sum_{k \in S} x^{k} & \geq v(S) & & \forall S \subset C \\
x^{k} & \geq 0 & \forall k \in C
\end{array}
$$

It should be noted that the EPM can only be applied to games where the core is non-empty. If the core is empty, other techniques, such as epsilon-core (Maschler et al., 1979), should be introduced to make the LP model feasible. In our computational tests, we found the core to be non-empty in all test instances.

\section{Nucleolus}

We define the excess of allocation $x$ for a coalition $S \subseteq C$ as $\theta(S, x)=\sum_{k \in S} x^{k}-v(S)$, which expresses the difference between the profit allocated to the participants in coalition $S$ and the coalition's stand-alone profit. A negative excess means that the coalition will be better off alone instead of staying in the grand coalition and accepting the allocation. The nucleolus is an allocation that satisfies the efficiency and individual rationality properties and has the lexicographically maximal associated excess vector (Schmeidler, 1969). The nucleolus always exists and is unique regardless of the core being empty or not. When the core is non-empty, the nucleolus is in the core. In order to compute the nucleolus one can solve a sequence of linear programs as explained by e.g. Guajardo and Jörnsten (2015).

\section{The Shapley value}

The Shapley value (Shapley, 1953) is defined for each participant as the weighted average of the participant's marginal contribution to each subset of the cooperation. The marginal contribution of participant $k$ to any coalition $S$, which does not include participant $k$ is:

$$
\Delta^{k}(S)=v(S \cup\{k\})-v(S)
$$

The profit allocated to participant $k$ is given by:

$$
x^{k}=\sum_{S \subseteq C \backslash\{k\}} \frac{|S| !|C \backslash(S \cup\{k\})| !}{|C| !} \Delta^{k}(S),
$$

where, $|\cdot|$ denotes the number of participants in the coalition considered. It should be noted that the Shapley allocation does not guarantee a core solution. However, it satisfies the efficiency and individual rationality properties, as well as some other properties, such as symmetry and additivity. It allocates nothing to a participant if the participant contributes nothing to all coalitions it is part of. 


\section{Equal charge method (ECM)}

According to Tijs and Driessen (1986), a profit can be divided into two types: separable profit and non-separable profit. The separable profit of participant $k$ is defined as its marginal profit with respect to the grand coalition, denoted as $m_{k}=v(C)-v(C \backslash\{k\})$. The non-separable profit is the remaining profit, calculated as $v(C)-\sum_{k \in S} m_{k}$. In the Equal Charge Method (ECM), the separable profit is first allocated to the corresponding participant and the non-separable profit is then distributed equally among the participants. Hence, the profit allocated to participant $k$ is $x^{k}=m_{k}+\frac{v(C)-\sum_{k \in N} m_{k}}{|C|}$, where $m_{k}=v(C)-v(C \backslash\{k\})$.

\section{Proportional to individual profit (P2I)}

This method allocates the profit of the grand coalition based on the stand-alone profit (individual profit) of each participant. The profit allocated to participant $k$ is $x^{k}=$ $\frac{v(\{k\})}{\sum_{i \in C} v(\{i\})} \cdot v(C)$. A similar method has been used for cost sharing in Frisk et al. (2010).

\section{Proportional to fleet size (P2S)}

The profit of the grand coalition can be allocated according to fleet size. Let $q_{k}$ denote the number of ships provided by participant $k \in C$. The profit allocated to $k$ is then given by $x^{k}=\frac{q_{k}}{\sum_{i \in C} q_{i}} \cdot v(C)$. This allocation method can be seen as a simple example of the weighting systems often employed in practice.

\section{Case study}

We obtained real-life data from a Danish product tanker pool, including the cargoes transported over a period of two years and information about the deployed ships. Based on the real-life data, we generated our datasets for testing the algorithm. In the real-life data, each order consists of one or several pickup ports and one or several delivery ports. The visiting sequence of these ports is fixed. Approximately $70 \%$ orders have one pickup port, $30 \%$ two pickup ports, and approximately $70 \%$ have one delivery port, $22 \%$ two delivery ports, $7 \%$ three delivery ports and $1 \%$ four delivery ports. We followed the same distribution when generating our datasets. For each order, one pickup and one delivery port, which are at least 1 kilometre apart, are initially selected based on their frequencies in real-life data. Extra pickup/delivery ports are selected among those ports which will increase the total distance by at most a factor of 1.3 when added. Additionally, a second pickup port must be within a limited distance of the first pickup port and vice versa for delivery ports in order to keep pickup and delivery ports grouped together. By doing so, the average length of all the orders will be too high, compared to the observed average in actual data, as can be seen from Figure 2, where the blue curve shows the distribution of the order length in real-life data and the red curve is generated by random port selection. In order to resemble the real data, we always generate excess orders with a distance less than 11,000 kilometres and use a subset of all the generated orders. The green curve in 


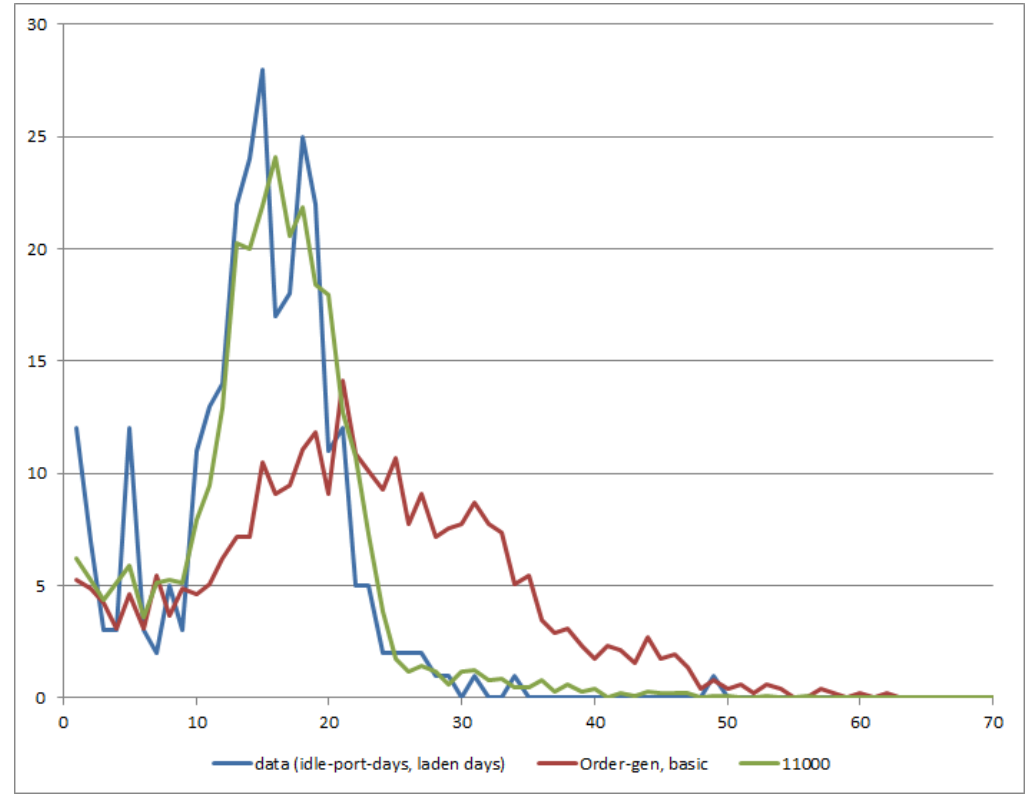

Figure 2: The distribution of order length in real data (in blue), generated data without adjustment (in red) and generated data with adjustment (in green).

Figure 2 represents the output after this adjustment, which is very close to the actual data.

The start of the pickup time window is randomly selected within the planning horizon, and the length of the time window is between one and four days, following a uniform distribution. As the problem is dynamic, not all orders are revealed from the beginning. Therefore, we also generate an awareness date, which is a random day between 1 and 14 days before the start of the time window.

In this work, we extend the practical problem to a more general case where the cargo owner specifies the preferred service speed and a range of acceptable service speeds, and the routing decision maker determines the service speed to be carried out in practice. We work with a set of discretised speeds $V=\{10,10.5, \ldots, 16\}$ knots $(1$ knot equals $1.852 \mathrm{~km}$ per hour). Each order's desired service speed is selected based on the service speeds in the real-life data. The acceptable speeds are generated as a random set of consecutive speeds embracing the desired speed.

The reward for serving an order at a certain speed is generated based on the sailing distance, the expected fuel consumption, the difference between the actual speed and the preferred speed, and a random element which follows a normal distribution with mean 1.05 and standard deviation 1.05 .

To analyse the cooperation in different market scenarios, data instances with different numbers of orders are generated, ranging from 250 to 1250 orders for a nine-month planning horizon.

There are a total of 32 ships in the shipping pool. The feasible sailing speeds and the corresponding fuel consumptions vary between ships. For example, one of the heavy and slow ships can sail between 12 and 15.5 knots, with a fuel consumption at 14 knots of 39.5 and 41.5 tons per day for ballast and laden sailing respectively, whereas a lighter 
ship will consume 29.5 and 34 tons per day at the same speed. The ship speeds and fuel consumption rates are real-life data provided by the product tanker pool.

The ships are provided by a set of shipping companies of varying size, but due to a lack of profitability ships are rarely operated alone in reality. Having single ship shippers in the analysis would thus create an unrealistic analysis of the impact of collaboration, and we therefore combine the smallest shippers into a single participant. Consequently, we assume four shipping participants in total in our simulation. The number of ships from each participant is given in Table 1.

\begin{tabular}{|c|c|}
\hline Participant & Number of ships \\
\hline \hline A & 13 \\
\hline B & 6 \\
\hline C & 5 \\
\hline D & 8 \\
\hline
\end{tabular}

Table 1: The number of ships contributed to the shipping pool by each participant.

\section{Computational results}

The proposed solution method was implemented in $\mathrm{C}++$ and the linear programming models corresponding to the EPM and nucleolus allocation methods are solved by CPLEX 12.6.1. The framework was tested on instances generated from real-life data. The data and the results are presented in this section.

\subsection{Simulation results}

All simulations cover 270 days, and for each test configuration (number of orders, coalition composition) 10 separate runs have been performed using a different random seed. A new set of orders is generated for each of these seeds. Each simulation run takes from 5 to 20 minutes depending on the number of orders, and the size of the set of participants.

Table 2 presents the average profit of each coalition over ten random instances for each instance size. The first column is the coalition ID. There are in total 15 coalitions, including the grand coalition formed by all four participants. Columns two to five indicate which participants are included in the coalition. Column 'N250' presents the average profit over the ten random instances with 250 orders each. The remaining columns show the results of the other instance sizes. The third row from the bottom is the total profit without cooperation, which is calculated as the sum of the individual profits, i.e., the sum of the profits of the first four coalitions in the table. The benefit of cooperation, i.e., the difference between the total profit without cooperation and the total profit of the grand coalition, is given in the second last row and the relative gain in the last row. As can be seen, the total profit has increased significantly, more than $25 \%$, through the centralized horizontal cooperation in all cases. This profit is larger than what is typically observed in profit sharing under horizontal collaborations. This is in part due to the way the orders are distributed, assuming each shipper brings their own orders. 
It should be noted that the profits shown are the revenues minus fuel costs in USD. This means that each individual participant will still have to pay wages, maintain the ships and possibly pay down on loans using the money reported as profit in the table.

However, it is clear that there is a notable benefit from collaboration in all the different scenarios. While we do not claim to know the true motive for forming shipping pools in practice, the results indicate that there are indeed financial benefits present, and not just advantages related to avoiding competition and controlling prices, as one might otherwise fear..

\subsection{Results on profit allocation}

The results of using the different profit allocation methods for all instances are given in Tables 3 to 5 . All solutions were obtained within less than a second. The first column shows the instance size and the second the participant ID. The third column presents individual profit, i.e., the profit of each participant without cooperation. For each allocation method, the table presents the profit allocated to each participant (Profit), the relative difference between the allocated profit and the individual profit $\left(\Delta_{1}\right)$, and the proportion of the total profit allocated to each participant $\left(\Delta_{2}\right)$. The row 'Stable' indicates whether the profit allocation is stable, i.e., satisfying constraint (17). Among the six allocation methods, only the nucleolus and EPM guarantee a stable allocation in theory. However, the Shapley value method also succeeds in finding stable allocations for all instances. The P2I method divides the profit proportionally to the individual profit, therefore the relative gain for each participant is the same. When the allocation given by the P2I method is stable, the allocation is the same as that of the EPM method.

In a real-life setting, one could argue for using most of the proposed methods, assuming that it is feasible to estimate the profits for sub-coalitions that are necessary for the more complex methods. The P2S method may seem a bit simple, but it is in fact not very different from the method used in practice today by the product tanker pool that has provided the case data for this paper. With that in mind, it is interesting how differently the various methods allocates profit. Switching from one profit allocation method to another can have a significant impact on a single participant. Consider for example participant $\mathrm{C}$ in the N500 test. Here the allocated profits range from 4.7 million to 7.4 million; a difference that would surely mean a lot to the shipping company. This also emphasizes the difficulties faced by the manager of a shipping pool when profits must be allocated. The pool will initially have decided upon a method for sharing the profits, but some participants in the collaboration might well wish to tweak the sharing method in order to get a bigger share of the profits.

It is difficult to recommend a single method for use in practice. We would like to highlight the nucleolus and EPM methods since they guarantee a solution in the core, but they are difficult to apply in practice, because they rely on knowing the profit that each sub-coalition could obtain if working independently. This profit could be estimated using a simulation framework like the one presented in this paper, but we acknowledge that the precision of the simulation may be debatable, and it would be difficult to convince all participants in the pool about the accuracy of the simulation. 


\subsection{Sensitivity to pool size}

To analyse how the pool size affects the solution quality, we tested the instances with different pool sizes. The number of ships ranges from 1 to 31 and the ships are randomly selected from the 32 ships present in the original scenario. The number of orders is set to $\frac{\mathrm{s}}{32}$. (number of orders for the grand coalition) rounded up or down randomly, where $s$ is the number of ships, and the orders are selected from the orders for the grand coalition. For each pool size, 10 random tests are performed. Figure 3 shows the average single ship profit over the random tests for different pool sizes and order densities. As the pool size increases, the average profit earned by each ship increases quickly in the beginning and then gradually flattens, since the pool size eventually reaches a certain point, where the ships are already utilized in an efficient manner and consequently any further increases bring only a limited benefit.

Figure 4 plots the magnitude of one standard deviation of observations as a function of the pool size. It shows that the variation in the outcomes is higher for smaller pool sizes, as they are much more sensitive to getting sets of orders that goes well together geographically and timewise.

The increase in profitability as a function of the number of ships in the pool is closely correlated to an increase in utilization as a function of the pool size which is plotted in Figure 5. It is also evident from Figure 5 that a larger amount of orders is associated with a higher profitability, though the effect is suffering from diminishing returns. This trend is even more evident when plotting the average percentage of sailing with cargo as a function of the number of orders in Figure 6 . The percentage of time spent sailing empty (Figure 7) increases initially as additional ships also bring additional orders to the pool, thus increasing the chance that an order fits well into a route, resulting in fewer orders being rejected due to lack of profitability. After a saturation point, the time spent sailing empty stabilizes. The time spent waiting must thus be a declining function to match the increase in the utilization, and this can be confirmed in Figure 8.

The profitability is thus more strongly correlated to an increased utilization, whereas the gain from decreasing fractions of time spent sailing empty only contributes marginally in some cases. Dependence on utilization rather than dependence on a decrease in empty sailing can be ascribed to the functioning of the solver for the routing problem. If an order cannot be served in a way that yields a profit, it is rejected, thus adding no empty sailing.

\section{Conclusion}

In this paper, we studied the effects of cooperation in a shipping pool consisting of product tankers. A key challenge for the operator of the pool is the choice of which orders to serve and how to assign orders to the different ships in the fleet. From an operations research point of view, this corresponds to solving a ship routing and order selection problem. The routing problem is of a dynamic nature since orders appear while the routing plan is being carried out. A simulator has been developed in order to handle the dynamic aspect and time periods of up to half a year have been simulated. Various setups corresponding to companies operating alone or together in pools have been simulated. 


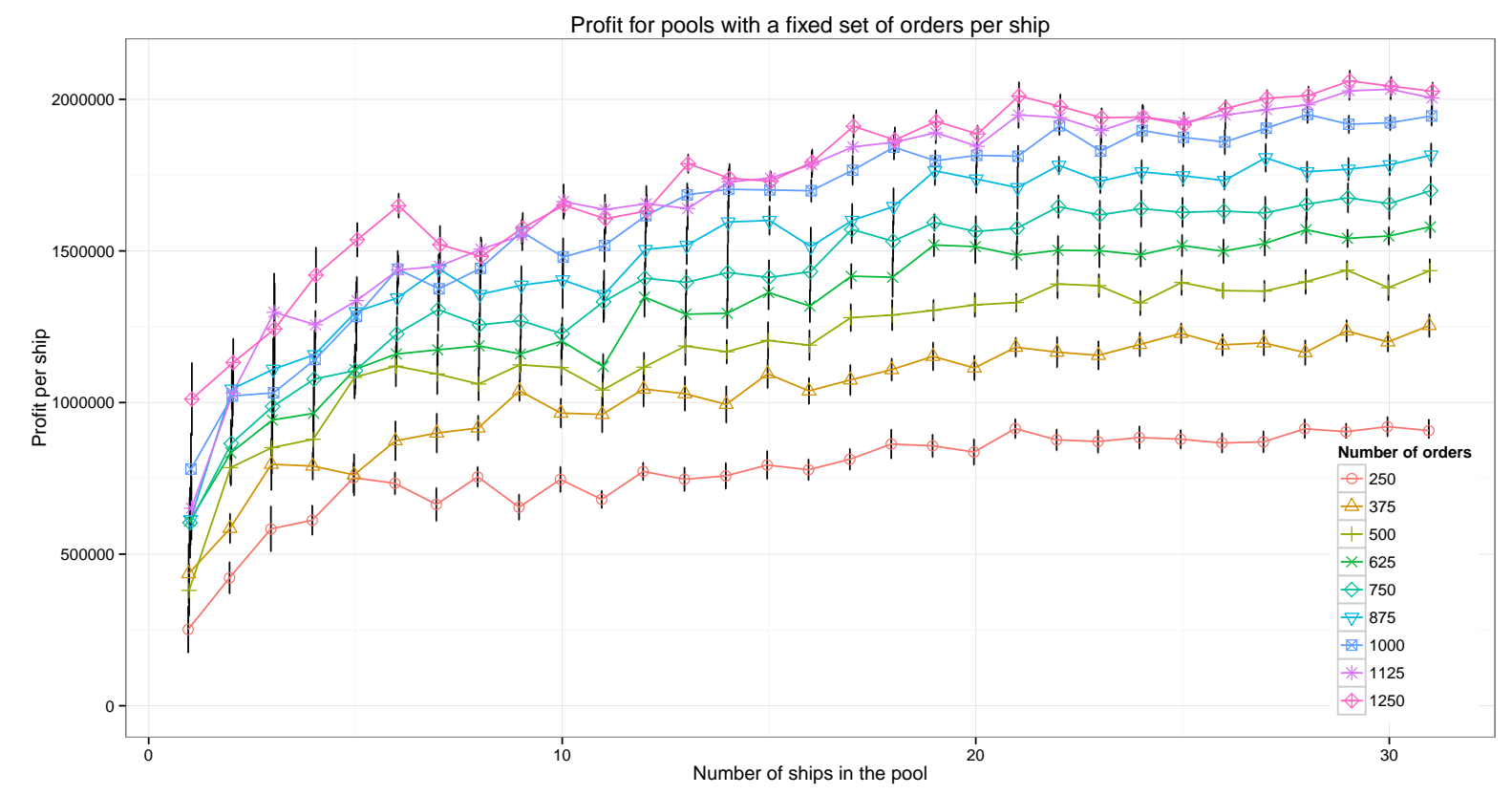

Figure 3: The effect of pool size on each ship's daily profit. One standard deviation indicated by a vertical line.

Through a large number of experiments, we evaluated the benefit of cooperation under different scenarios, presented the results of various profit allocation methods, and analysed the effect of pool size on the total profit and ship utilization. The benefit of collaboration was very clear in all cases considered. Based on the experiments it seems likely that entering a (well-managed) shipping pool would be a good decision for a smaller tanker shipping company that finds itself struggling to make a profit.

The benefits of pooling ships observed in this work are twofold. First, the pool can operate more efficiently allowing for a higher expected profitability, and second, the variation in outcomes decrease significantly as the pool size grows, minimising the risk of worst-case scenarios. None of these factors can be attributed to market dominance, as such factors were not modelled.

The profit allocations used in this work are not meant to be directly practically applicable, as they require not only knowing the profit of the grand coalition but also the profit of the rest of the coalitions. They do however demonstrate the existence of a set of allocations that are considered stable in the sense that no participant in the coalition has an incentive to leave by greater profit margins when operating alone. Choosing between the allocation methods is a highly political task, which lies outside of the scope of this paper.

Another interesting point is the allocation of orders to the coalition. In this paper, we let each ship "own" a number of orders that it will bring to each coalition it is part of. This is a simplification and in future work it would be interesting to simulate a market where competing entities are trying to win orders and investigate if the benefit of collaboration is even higher in such a setting. 


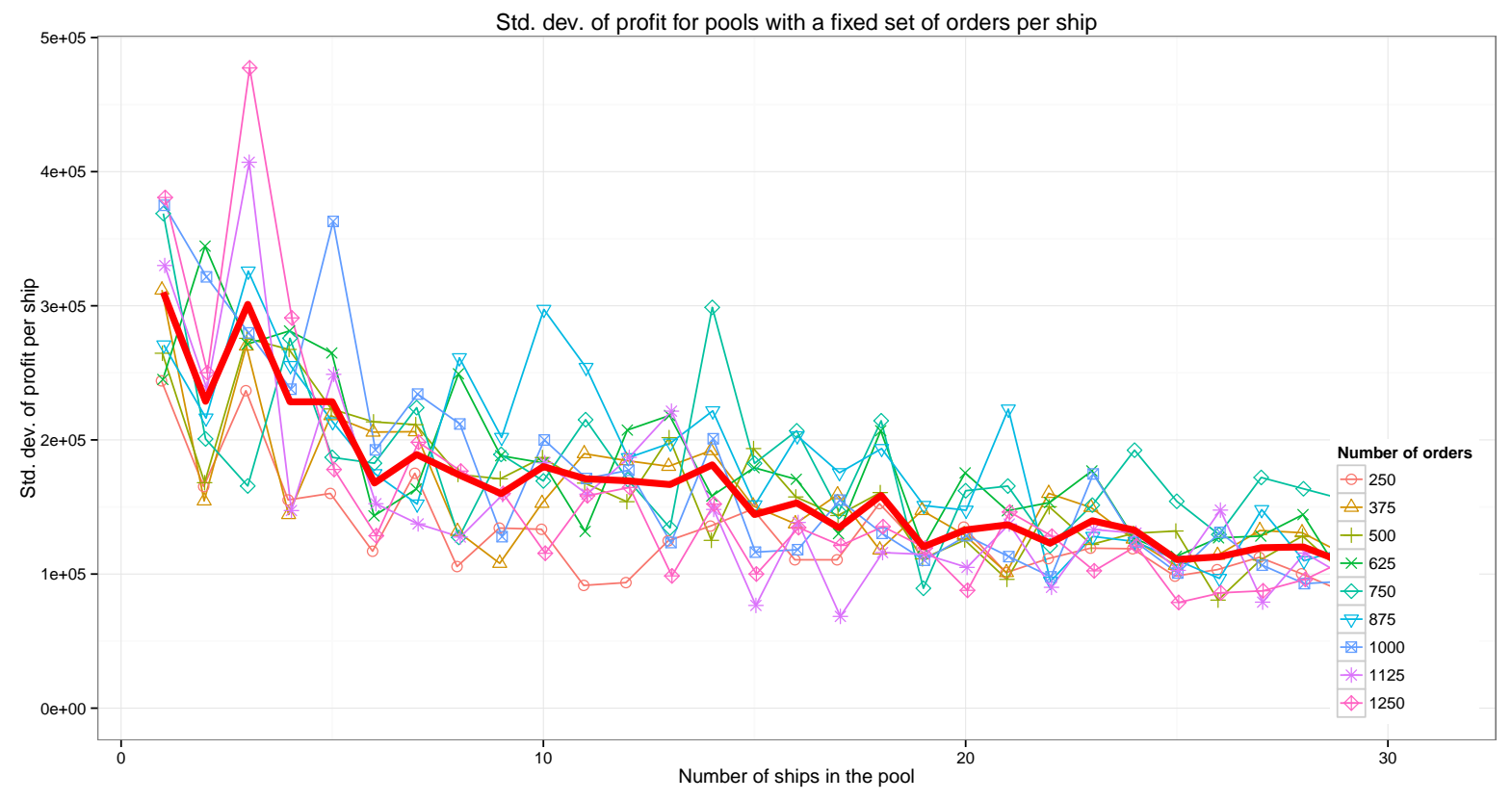

Figure 4: The effect of pool size on the standard deviation of the measurements. The bold line is the mean.

\section{Acknowledgement}

This work was partially supported by the Danish Maritime Fund, The Danish Strategical Research Council and The Danish Energy Technology Development and Demonstration Program (EUDP) under the ENERPLAN and GREENSHIP project and by the National Natural Science Foundation of China (No. 11601436). This support is gratefully acknowledged. The authors would also like to thank the anonymous referees for their valuable comments. 


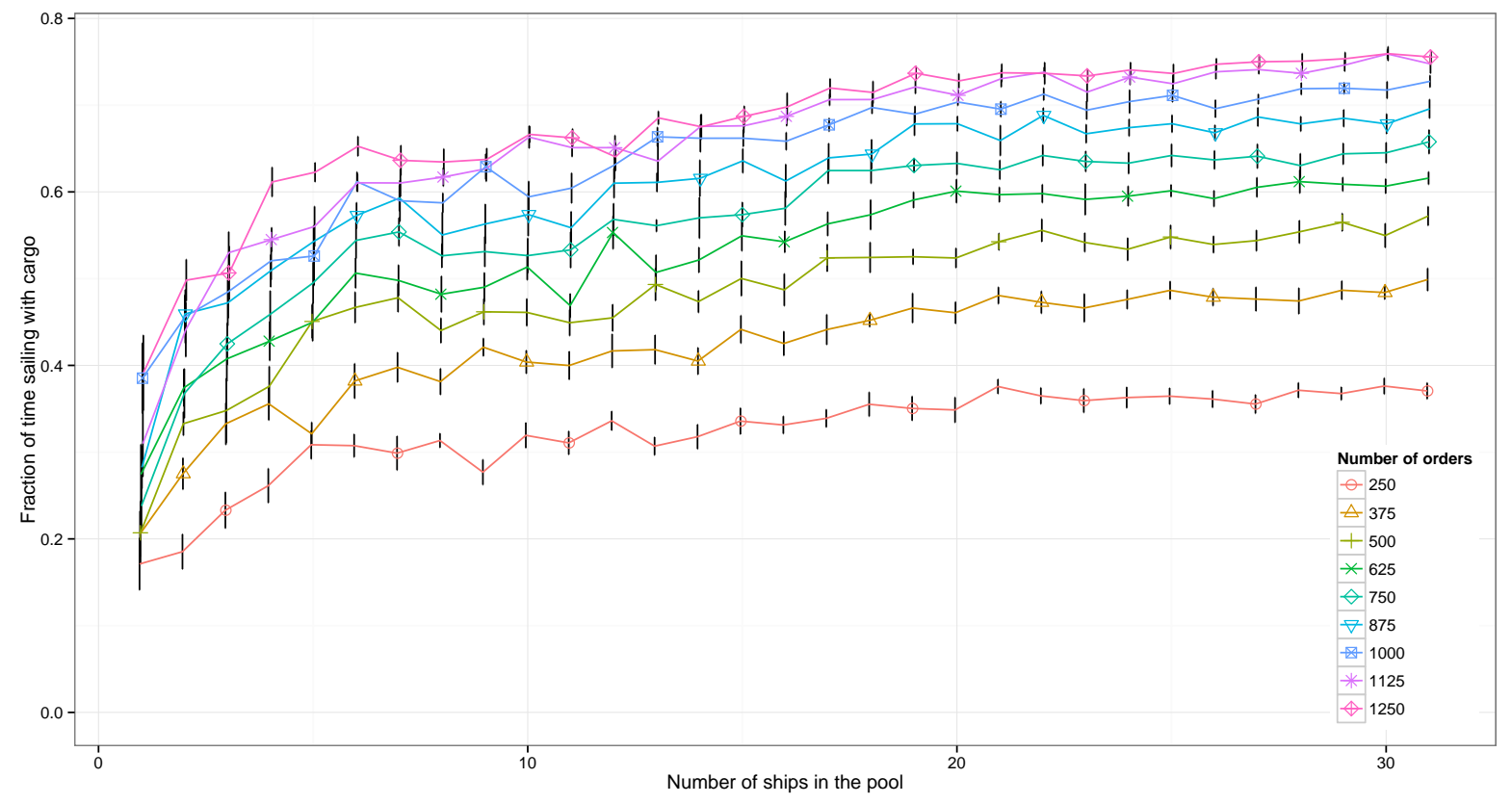

Figure 5: The effect of pool size on ships' time spent sailing with cargo. One standard deviation indicated by a vertical line.

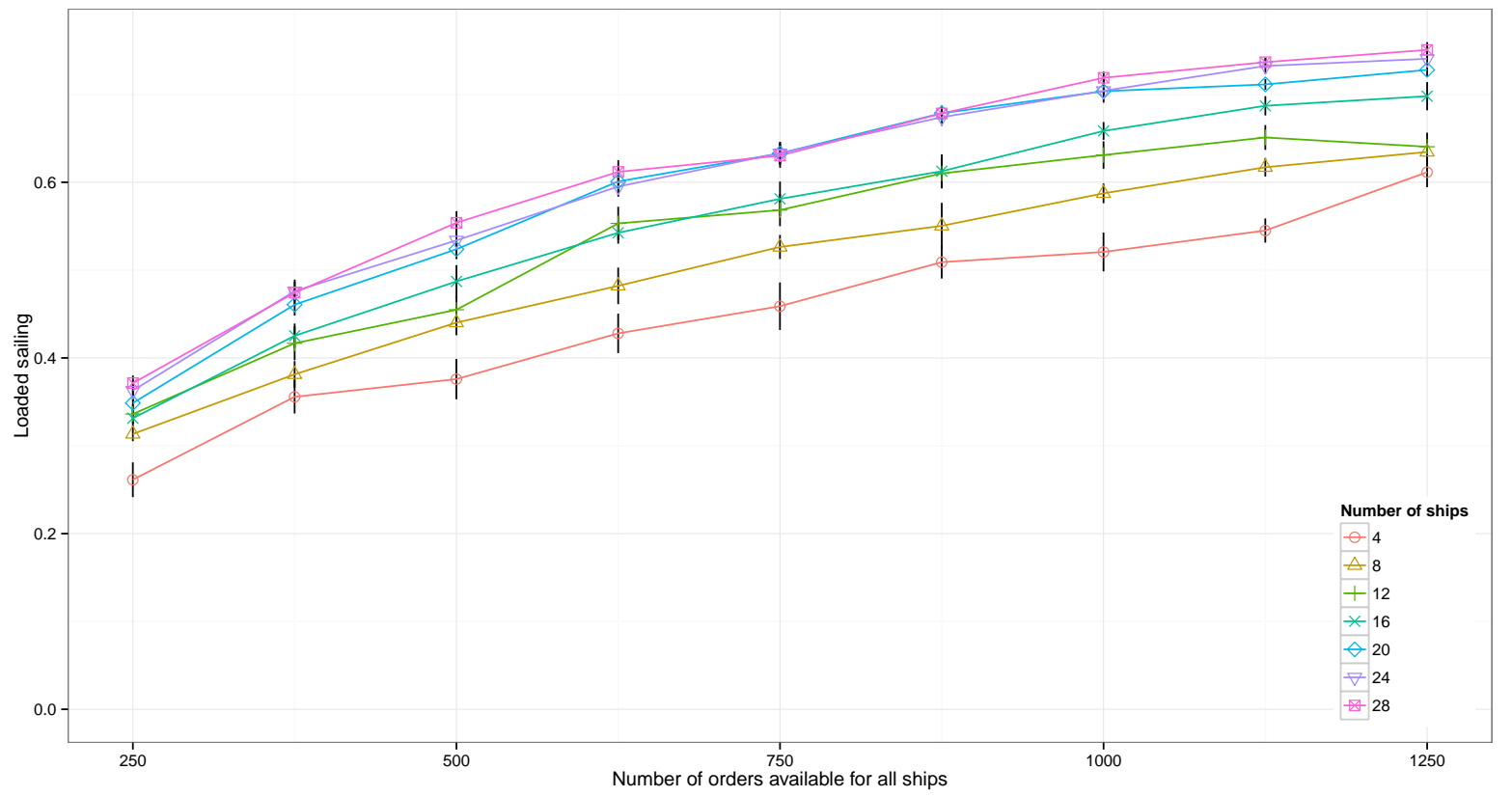

Figure 6: The effect of pool size on ships' utilization. One standard deviation indicated by a vertical line. 


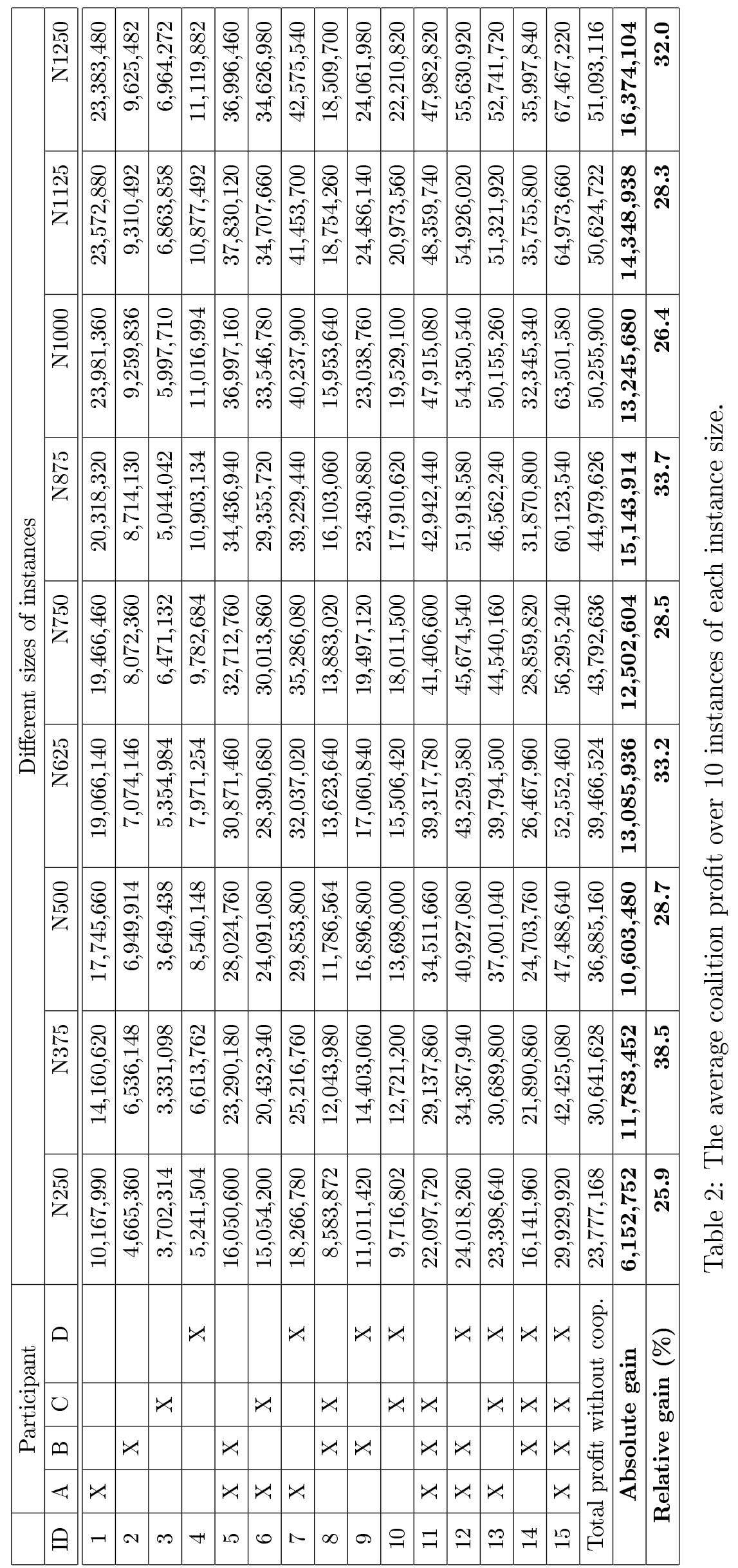




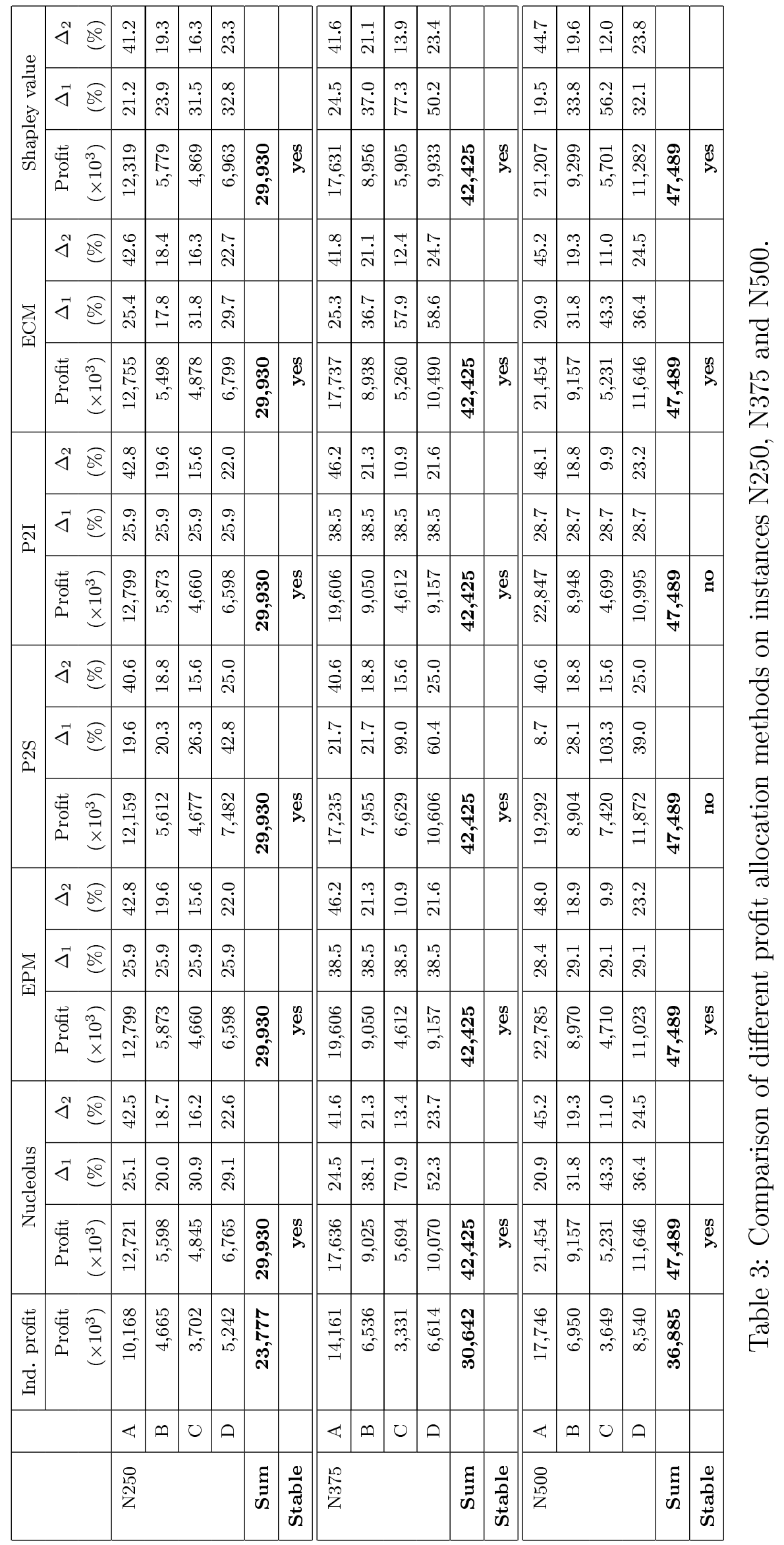




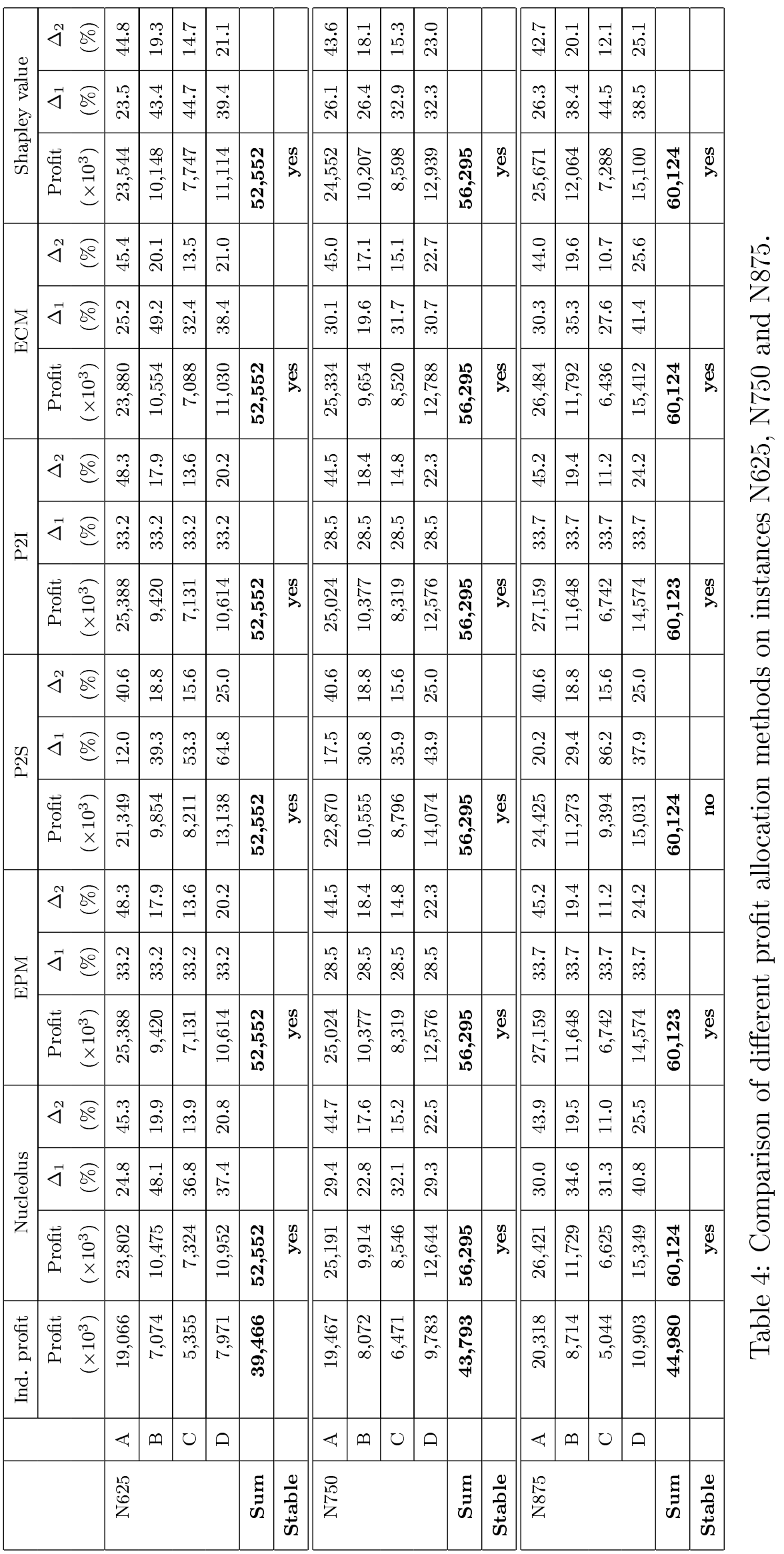




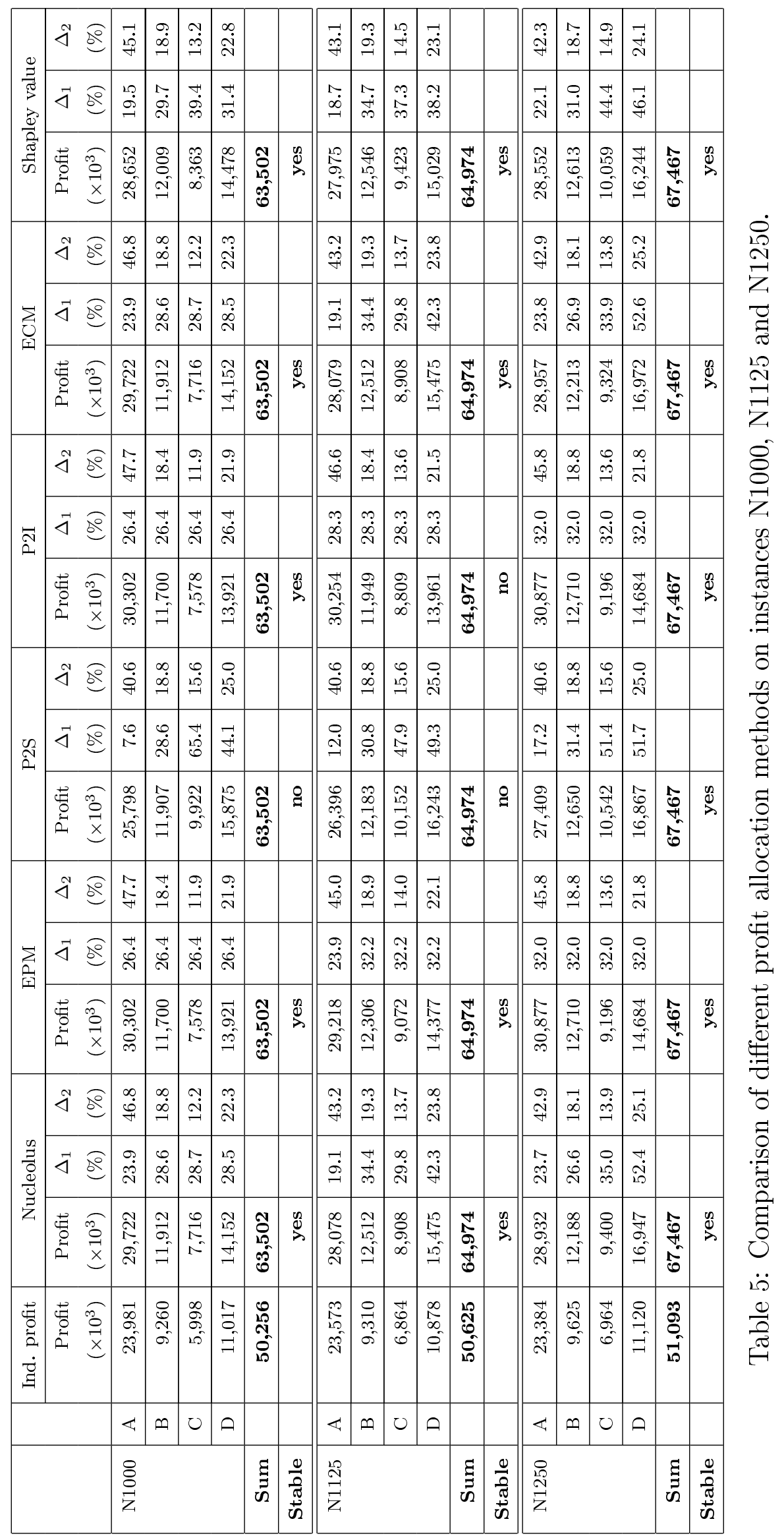




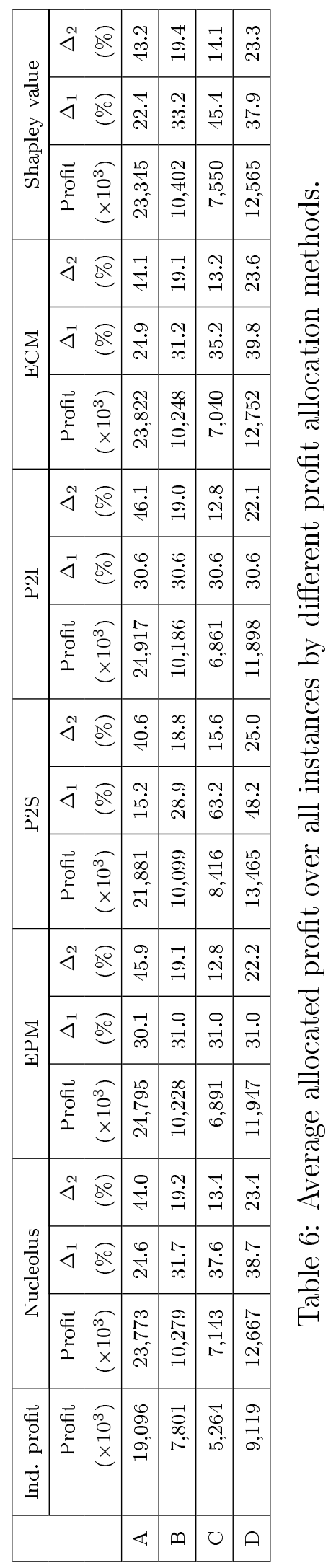




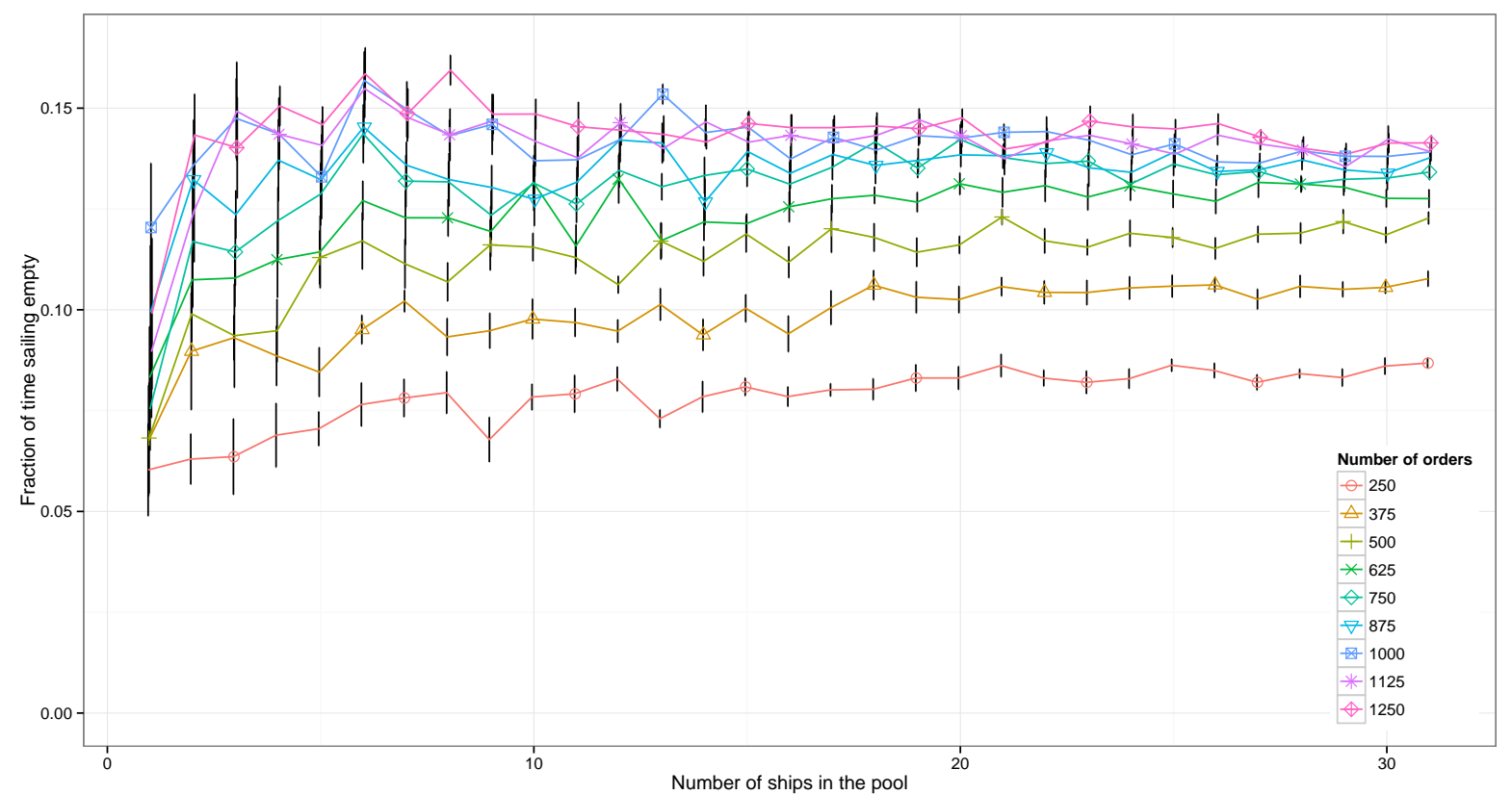

Figure 7: The effect of pool size on ships' time spent sailing empty. One standard deviation indicated by a vertical line.

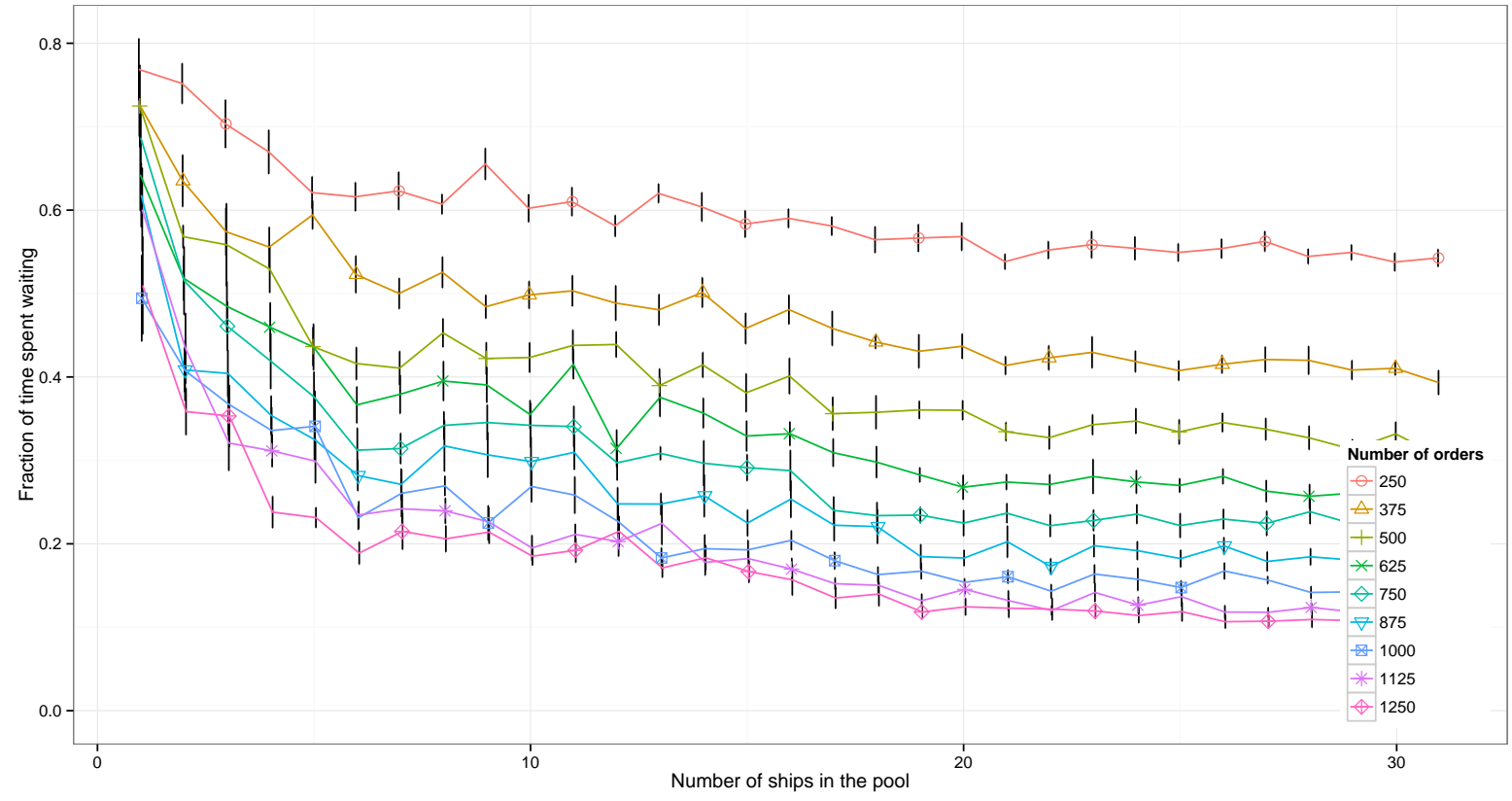

Figure 8: The effect of pool size on ships' time spent waiting. One standard deviation indicated by a vertical line. 


\section{References}

Agarwal, R. and Ergun, O. (2010a). Network design and allocation mechanisms for carrier alliances in liner shipping. Operations Research, 58(6):1726-1742.

Agarwal, R. and Ergun, Ö. (2010b). Network design and allocation mechanisms for carrier alliances in liner shipping. Operations Research, 58(6):1726-1742.

Audy, J.-F., D'Amours, S., and Rousseau, L.-M. (2011). Cost allocation in the establishment of a collaborative transportation agreement-an application in the furniture industry. Journal of the Operational Research Society, 62(6):960-970.

Bektas, T., Repoussis, P., and Tarantilis, C. (2014). Dynamic vehicle routing problems. In Toth, P. and Vigo, D., editors, The vehicle routing: problems, methods, and applications,, page 299šC348. MOS-SIAM series on optimization, society for industrial and applied mathematics.

Christiansen, M., Fagerholt, K., Nygreen, B., and Ronen, D. (2013). Ship routing and scheduling in the new millennium. European Journal of Operational Research, 228:467483.

Clarkson Research Studies (2004). The tramp shipping market. http://www.pfri . uniri.hr/ bopri/documents/Unit26-TRAMPSHIPPINGMARKET_000.pdf.

Cruijssen, F., Cools, M., and Dullaert, W. (2007). Horizontal cooperation in logistics: Opportunities and impediments. Transportation Research Part E-Logistics and Transportation Review, 43(2):129-142.

Cruijssen, F., Dullaert, W., and Joro, T. (2010). Freight transportation efficiency through horizontal cooperation in Flanders. International Journal of Logistics-Research and Applications, 13(3):161-178.

Ergun, O., Kuyzu, G., and Savelsbergh, M. (2007a). Reducing truckload transportation costs through collaboration. Transportation Science, 41(2):206-221.

Ergun, O., Kuyzu, G., and Savelsbergh, M. (2007b). Shipper collaboration. Computers \& Operations Research, 34(6):1551-1560.

Fagerholt, K., Heimdal, S., and Loktu, A. (2000). Shortest path in the presence of obstacles: An application to ocean shipping. Journal of the operational research society, 51(6):683-688.

Frisk, M., Göthe-Lundgren, M., Jornsten, K., and Ronnqvist, M. (2010). Cost allocation in collaborative forest transportation. European Journal of Operational Research, 205(2):448-458.

Gatica, R. A. and Miranda, P. A. (2011). Special Issue on Latin-American Research: A Time Based Discretization Approach for Ship Routing and Scheduling with Variable Speed. Networks \& Spatial Economics, 11(3, SI):465-485. 
Guajardo, M. and Jörnsten, K. (2015). Common mistakes in computing the nucleolus. European Journal of Operational Research, 241(3):931-935.

Haralambides, H. E. (1996). The economics of bulk shipping pools. Maritime Policy and Management, 23(3):221-237.

Hwang, H.-S., Visoldilokpun, S., and Rosenberger, J. M. (2008). A branch-and-price-andcut method for ship scheduling with limited risk. Transportation science, 42(3):336-351.

Korsvik, J. E., Fagerholt, K., and Laporte, G. (2010). A tabu search heuristic for ship routing and scheduling. Journal of the Operational Research Society, 61(4):594-603.

Krajewska, M. A., Kopfer, H., Laporte, G., Ropke, S., and Zaccour, G. (2008). Horizontal cooperation among freight carriers: request allocation and profit sharing. Journal of the Operational Research Society, 59(11):1483-1491.

Lin, D.-Y. and Liu, H.-Y. (2011). Combined ship allocation, routing and freight assignment in tramp shipping. Transportation Research Part E-Logistics and Transportation Review, 47(4):414-431.

Maschler, M., Peleg, B., and Shapley, L. S. (1979). Geometric properties of the kernel, nucleolus, and related solution concepts. Mathematics of Operations Research, 4(4):303338 .

Norstad, I., Fagerholt, K., and Laporte, G. (2011). Tramp ship routing and scheduling with speed optimization. Transportation Research Part C-Emerging Technologies, 19(5, SI):853-865.

Özener, O. O., Ergun, O., and Savelsbergh, M. (2011). Lane-exchange mechanisms for truckload carrier collaboration. Transportation Science, 45(1):1-17.

Packard, W. V. (1995). Shipping Pools. Lloyd's of London Press.

Pillac, V., Gendreau, M., Guéret, C., and Medaglia, A. L. (2013). A review of dynamic vehicle routing problems. European Journal of Operational Research, 225(1):1-11.

Psaraftis, H. N. and Kontovas, C. A. (2013). Speed models for energy-efficient maritime transportation: A taxonomy and survey. Transportation Research Part C: Emerging Technologies, 26(0):331 - 351 .

Psaraftis, H. N., Wen, M., and Kontovas, C. A. (2016). Dynamic vehicle routing problems: Three decades and counting. Networks, 67(1):3-31.

Rodrigo, J. (2007). New EU regulation on the application of the articles 85 and 86 of the treaty as regards to the maritime transport tramp services competency and pools. In Osés, F. X. M. d. and Dauer, R. R.-M., editors, 5th International Congress on Maritime Technological Innovations and Research, pages 601-612. Departament de Ciència i Enginyeria Nàutiques, Universitat Politècnica de Catalunya. 
Saeed, N. and Larsen, O. I. (2010). An application of cooperative game among container terminals of one port. European Journal of Operational Research, 203(2):393-403.

Schmeidler, D. (1969). The nucleolus of a characteristic function game. Siam Journal on Applied Mathematics, 17(6):1163-1170.

Schmoltzi, C. and Wallenburg, C. M. (2011). Horizontal cooperations between logistics service providers: motives, structure, performance. International Journal of Physical Distribution $\&$ Logistics Management, 41(5-6):552-576.

Shapley, L. S. (1953). A value for n-person games. In Kuhn, H. W. and Tucker, A. W., editors, Contributions to the Theory of Games, Volume II, volume 28 of Annals of Mathematics Studies, pages 307-317. Princeton University Press.

Sherali, H. D. and Lunday, B. J. (2011). Equitable apportionment of railcars within a pooling agreement for shipping automobiles. Transportation Research Part E: Logistics and Transportation Review, 47(2):263-283.

Song, D.-W. and Panayides, P. M. (2002). A conceptual application of cooperative game theory to liner shipping strategic alliances. Maritime Policy \& Management, 29(3):285301.

Tijs, S. H. and Driessen, T. S. (1986). Game theory and cost allocation problems. Management Science, 32(8):1015-1028.

Tirado, G. and Hvattum, L. M. (2016a). Determining departure times in dynamic and stochastic maritime routing and scheduling problems. Flexible Services and Manufacturing Journal, pages 1-19.

Tirado, G. and Hvattum, L. M. (2016b). Improved solutions to dynamic and stochastic maritime pick-up and delivery problems using local search. Annals of Operations Research, pages $1-19$.

Tirado, G., Hvattum, L. M., Fagerholt, K., and Cordeau, J.-F. (2013). Heuristics for dynamic and stochastic routing in industrial shipping. Computers $\&$ Operations Research, 40(1):253-263.

Toth, P. and Vigo, D. (2014). Vehicle routing: problems, methods, and applications, volume 18. Siam.

Wen, M., Ropke, S., Petersen, H. L., Larsen, R., and Madsen, O. B. G. (2016). Fullshipload tramp ship routing and scheduling with variable speeds. Computers \& Operations Research, 70:1-8.

Willems, P., Macharis, C., Breedam, A. V., Vannieuwenhuyse, B., and Waeyenbergh, G. (2010). Managing information flows in horizontal collaboration for an optimised and more sustainable supply chain performance. In Proceedings of the 12th World Conference on Transportation Resesarch, Lisbon, Portugal. 
Xu, F., Lu, H., Ding, N., and Liu, J. (2015). Game theory analysis of container port alliance. Journal of Coastal Research, 73(sp1):635-640.

Yang, D., Liu, M., and Shi, X. (2011). Verifying liner shipping alliance's stability by applying core theory. Research in Transportation Economics, 32(1):15-24. 